\title{
GUILLAUME BERTHON, La curée contre le chancelier Guillaume Poyet (1542-1545): Clément Marot et les coq-à- l'âne
}

\section{Filippo Fassina}

\section{(2) OpenEdition}

\section{Journals}

Edizione digitale

URL: https://journals.openedition.org/studifrancesi/47045

DOI: $10.4000 /$ studifrancesi. 47045

ISSN: 2421-5856

Editore

Rosenberg \& Sellier

\section{Edizione cartacea}

Data di pubblicazione: 1 décembre 2021

Paginazione: 594-595

ISSN: 0039-2944

\section{Notizia bibliografica digitale}

Filippo Fassina, "GUILLAUME BERTHon, La curée contre le chancelier Guillaume Poyet (1542-1545): Clément Marot et les coq-à-l'âne», Studi Francesi [Online], 195 (LXV | III) | 2021, online dal 01 décembre 2021, consultato il 07 décembre 2022. URL: http://journals.openedition.org/studifrancesi/47045 ; DOI: https://doi.org/10.4000/studifrancesi.47045

Questo documento è stato generato automaticamente il 7 décembre 2022.

\section{cc) (1)}

Creative Commons - Attribuzione - Non commerciale - Non opere derivate 4.0 Internazionale - CC BYNC-ND 4.0

https://creativecommons.org/licenses/by-nc-nd/4.0/ 


\title{
GUILLAUME BERTHON, La curée contre le chancelier Guillaume Poyet (1542-1545): Clément Marot et les coq-à-l'âne
}

\author{
Filippo Fassina
}

\section{NOTIZIA}

GUILLAUME BERTHON, La curée contre le chancelier Guillaume Poyet (1542-1545): Clément Marot et les coq-à-l'âne, "Bibliothèque d'Humanisme et Renaissance", LXXXI, 3 (2020), pp.

443-452.

1 Come corollario del precedente contributo (G. Berthon, E. Doudet, Le recueil Grenet: collection poétique, pratiques littéraires et réseaux culturels (Genève, XVI siècle), "Bibliothèque d'Humanisme et Renaissance", LXXXI, 3 (2020), pp. 419-442), viene offerta un'analisi approfondita di alcuni testi contenuti nel manoscritto Grenet (M 1016), conservato alla Bibliothèque cantonale et universitaire di Losanna. Si tratta nello specifico di un epigramma intitolato Dizain de Marot, du chancelier Guillaume Poyet, di un quatrain e di un secondo epigramma, questa volta un douzain. Tutti questi componimenti sembrerebbero fare riferimento al cancelliere Guillaume Poyet: questi, obligé di Anna di Montmorency e divenuto primo presidente del Parlamento nel 1538, si schiera apertamente contro l'Ammiraglio Chabot e contribuisce attivamente al suo arresto. Tuttavia, la caduta in disgrazia di Montmorency porta al declino anche di Poyet, arrestato nel 1542 e condannato a cinque anni di carcere in un processo in cui anche Francesco I figura fra i testimoni dell'accusa. Per quanto riguarda i testi analizzati in questo lavoro, il quatrain, attribuito con certezza a Marot, sembrerebbe riferirsi con buona probabilità proprio a questa condanna, anche se spesso i critici hanno confuso la figura di Poyet con quella del più celebre Étienne Dolet. Sul dizain sono invece stati sollevati numerosi dubbi relativamente alla sua attribuzione a Marot: l'A. tuttavia sostiene con certezza, sulla base della presenza delle medesime tematiche, che si tratti 
di due componimenti dello stesso autore. Resta invece ancora incerta la paternità del douzain. Il tema della caduta di Poyet è costante nella produzione di Marot, tanto che nel presente lavoro vengono repertoriati altri testi (in particolare dei coq-à-l'âne) in cui sono presenti probabili allusioni all'arresto del cancelliere: di questi componimenti vengono forniti interessanti esempi testuali. Infine, l'A. ipotizza un'interessante coincidenza: qualche mese dopo la condanna, Rabelais ottiene il privilège per la pubblicazione dei primi due libri di Gargantua e Pantagruel e del Tiers Livre, in cui si ritrova un'aspra critica alla corruzione del parlamento di Lione, che potrebbe essere stata ispirata proprio dalla caduta di Guillaume Poyet. 